\title{
Study of the Development of Youth Culture under the Background of Advanced Culture
}

\author{
Yang Yang \\ Southwest University, Chongqing, China \\ Email: yangyangtangxin@vip.qq.com
}

Received October $14^{\text {th }}, 2013$; revised November $22^{\text {nd }}, 2013$; accepted December $19^{\text {th }}, 2013$

\begin{abstract}
Copyright (C) 2014 Yang Yang. This is an open access article distributed under the Creative Commons Attribution License, which permits unrestricted use, distribution, and reproduction in any medium, provided the original work is properly cited. In accordance of the Creative Commons Attribution License all Copyrights (C) 2014 are reserved for SCIRP and the owner of the intellectual property Yang Yang. All Copyright (c) 2014 are guarded by law and by SCIRP as a guardian.
\end{abstract}

\begin{abstract}
It refers to the sum total of value system, behavioral norms and social relationships accepted by young generations for youth culture which has the characteristic of hierarchy, variability and rebellion. It has also had positive and negative functions. It is the mutual influence and mutual promoting relationship between the youth culture and advanced culture. Comrade Hu Jintao puts forward three wishes to the majority of young people, but also gives the youth culture three new elements, which are diligent in learning, good at creating and making contribution. In the new period, the youth culture will further be boosted when we are developing advanced culture.
\end{abstract}

Keywords: Youth Culture; Advanced Culture; Development

\section{Introduction}

Researches on youth issues appeared with industrialization, urbanization and modernization. As early as 1904, Hall, the father of child psychology in the United State, had published a monograph titled adolescence, which is thoroughly discussed about some youth issues, such as the changes of adolescent body, psychology and emotion, their desire for love, their feelings for nature, their interest for literature, biographies and history, their intellectual development, the social relationships, adult ceremony, youth crime and so on (Wei, 1996). In the early 1980s, youth sociology that had gained a firm footing in China as a discipline was established the foundation for the study of Chinese youth culture. There is little information available in literature about the youth culture. For the concept of youth culture, different scholars hold different views. Some scholars believe that the youth culture is a way of life for the youth. Some think that it is the sum total of all the lifestyles of youth groups. Others consider that it is the culture of young students and so on (Yao, 2000). In these different concepts, some are too broad and vague and some are too narrow. None of the other phases have been examined in detail. We conducted this paper to investigate the concept, characteristics and functions of youth culture, and to explore how to further prosper youth culture under the background of advanced culture in new period.

\section{The Definition, Characteristics and Functions of Youth Culture}

Its definition and characteristics The character of time is the character of the young. Youth is the main force of social life and the backbone of society in the future. The young age is a life period filled with of fantasy, excitement, mystery and loneliness. Nowadays, the youth culture in China is a special subculture that is closely related to the background of mainstream culture and the society, which regulated by its time, significant transformation and short transition. For the concept of youth culture, different scholars hold different views. Some scholars believe that the youth culture is a way of life for the youth, those think that it is the sum total of all the lifestyles of youth groups, others consider that it is the culture of young students and so on (Yao, 2000). In these different concepts, some are too broad and vague and some are too narrow. The socalled youth culture is the sum total of the acceptable value system, behavioral norms and social relationships shared by young groups. Relatively speaking, the youth culture refers to a special subculture representing youth and its society, it is different from the subject culture that contains the state which reflects the will of all citizens, the social formal organization which is represented by school and the family which is represented by parents.

Youth culture has characteristics of hierarchy, changeability and rebellion (Hao, 1996). Its hierarchy is embodied that it can be generally divided into the following three levels. The first level is a variety of a specific youth lifestyle and phenomena, such as the external quality of language, words, music, art, film, fashion, lifestyle, taste, etc. The second level is the value implied in the above-mentioned phenomena, and it can be roughly summarized by six aspects of experiential value, moral value, religious value, political value, scientific value and aesthetic value. The third level is the youth cognitive intention, aesthetic taste and psychological change trend, which are limited by these concepts and have not been theorized and systematized. Its changeability is resulted by the fact that youth is a transition period (José, 2001). Fei Xiao tong said that there are two kinds 
of different types for culture, one is a kind of culture to expand, the other is a kind of culture to give birth to shell and cease to grow (Fei, 1985). Youth culture belongs to the former. It firstly is reflected in the first level and is the external appearance of youth culture, and it is changeable. To a certain extent, this expanding culture has a subtle inner link with the youth values. It is usually the most important basis to observe the youth culture for the second level. Because these values are directly reflected the status and roles of the young in society. These values are essentially a kind of the evaluation standard and a kind of the more solid and enduring belief that can determine a young people to choose what kind of life form and behavior patterns in groups to judge right and wrong, beauty and ugliness, love and hate, etc. However, sometimes they will be changed over time, and even be rapidly changed in a short period. The general basis of modern youth culture is together made up of the third level and the objective background of the period, the social environment and the traditional cultural in which the youth live, which also has the characteristic of change. Its trait of rebellion means that youth who is always curious about the new things and won't be conformist and atavistic, recognize the traditional and modern society by themselves and express their ideas from their own perspective. So, a certain rebellion and deviation against mainstream culture will be emerged. Its rebellion is fully reflected in its vanguard and emotion ( $\mathrm{Li}, 1997)$. Parsons believes that the youth culture is an independent cultural system all shared by the young. A different degree kind of irresponsible youth culture has conflicts with the adult concepts which emphasis the duty, obedience and productive labor and youth culture stresses the uninhibited lifestyles and resists the hopes and constraints from the adults (Huang, 1993).

Its functions From the perspective of structural functionalist, youth culture, as a part of social consciousness, assumes some social functions that have both positive and negative sides. About the positive features, youth culture is necessary for the survival of social consciousness and has made a positive contribution to it. Firstly, youth culture can be beneficial to economic and social development. Then, it may create an active and rich social life. Meanwhile, it also can promote the cultural progress, consciousness changes, and shape new values. It as well can create a new life and form a new lifestyle. Specific to the youth, youth culture can help the young to do the self-realization and develop the personality. It may assist them in gaining recognition from groups. Besides, it also can satisfy their divergent needs and improve the life quality and so on. About the reverse function, youth culture may waste the social resources, and to some extent, it increases social costs. Specific to youth again, youth culture may make youth lose themselves, waste money and even cause a bad motive and behavior. Then, from the perspective of structural functionalist, youth culture lets young people have their own culture, helps them to have self-realization and satisfy their individual needs, and at the same time makes the young people release a certain degree of confusion about the society and the reality. All of these achieve the function of culture as a safety valve to the whole society.

\section{Developing the Advanced to Further Boost the Youth Culture}

Young people are the hope of the motherland and the nation. Mao Zedong, Deng Xiaoping and Jiang Zemin all have made many brilliant expositions about the youth and youth work, which reflects the Chinese Communist Party has a high attention, enthusiasm and ardent hope to the youth and also shows the importance of youth to a state or nation. Youth, who are the main force of the great rejuvenation of the Chinese nation and the national reunification, take on the significant task of building a moderately prosperous society. Therefore, correctly guiding, supporting and booming the youth culture is the important step to cultivate mainstay for modernization construction.

The relationship between advanced culture and youth culture Advanced culture and youth culture are the dialectical relation of mutual influences and mutual promotion. Advanced culture is a result of the human civilization's progress and historical development, is the thought basis, the spiritual motive power and intellectual supporting to promote the progress of human society. The culture's power is deeply rooted in the nation's vitality, creativity and cohesion. The youth culture is influenced by advanced culture. Advanced culture makes its national, scientific and popular socialist thought toward modernization, the world and the future into the youth culture by osmosis. Because youth culture is their own culture for the young people and deeply influences their values, cognitive, aesthetic and psychological tendence, and will further affect their socialism practice in future, such as to build an advanced civilization of socialism, the development of the advanced productive forces and to achieve the socialist modernization strategic task. Only by strengthening the advanced mainstream culture of Three Representatives, it can provide the final standard of the core idea and the value selection for the society and the youth. The young people are improved themselves by the mainstream culture to get the noble pursuit, the positive way of life and behavior and they will really be the hope of nation and society and really become the spokesperson of society and nation.

In turn, the advanced culture is also influenced by the youth culture. As the young people possess their self-esteem, self-respect, self-confidence, self-reliance and have a high spirit and noble character, the advanced culture is pour into a fresh impetus by their pioneering and creative spiritual culture. It will make us cohering public feeling and refreshing, and it will comprehensively boom the economic construction and other undertakings in our country. With the tendency of society becoming more younger and young' experience tends to be consistent, youth culture and the social mainstream culture showed the tendency to be close and mix together. Youth culture no longer has the property that the previous youth culture have the simple and generally not have the mainstream cultural characteristics, but it has the characteristics of the mainstream culture in some degree. In such conditions, it has been greatly improved for the reaction that the mainstream culture is influenced by the youth culture.

Define the advanced culture Youth culture, which is destined to change-forward or backward, cannot be stagnant. Advanced culture determines the youth culture. Culture also follows the law that everything is from less advanced to advanced, but to what extent can we consider that culture is advanced? In history, many scholars have made exploration and statements about the criterion of the advanced culture. For example, the American anthropologist Morgan stated that culture has three stages which are barbarism, half-civilization and civilization, and each stage was divided into low, intermediate and high levels of evolutionary concept. There is a typical view that Popenoe divided the culture into the material culture, cognitive culture and cultural norms. In cultural anthropology, culture has been classified into the material culture, spiritual culture and 
institutional culture. Besides, Marxism divided the social patterns scientifically with the mode of production and regarded the development level of productive forces as the symbol of advanced culture. Thus, the Three Represents itself is a manifestation of advanced culture. Youth culture is bound to accept the Three Represents, and then continues its life on the right path.

Strengthen the guidance of advanced culture Now, China is in the changing period which is comprehensive and multilatitude, the social administration system is switching from the highly centralized planned economic system to the socialist market economic system. In terms of the social structure, the society is changing from the agricultural, rural, closed and semi-closed traditional society to the industrial, urban and open modern society. During this process, some young people may misunderstand the traditional culture and public morality, and then violate the social rules. However, we can prevent these problems effectively through the guidance of advanced culture. Firstly, youth culture, which is affected by the advanced culture and also has deeply rooted in the country's advanced culture, develops in accordance with the advanced culture. Secondly, weakening advanced culture can make subculture lose support and the youth culture may turn into its opposite. Meanwhile, the young generation may also feel depressive and lose themselves in social life, from which one can easily image the characteristics of youth. According to the dialectical relationship between them, the cultural ecological balance must be the multi-culture which is guided by the advanced mainstream culture. Otherwise, multiculturalism may lead the cultural confusion.

Finally, to prevent the cultural confusion, we should develop advanced culture and strengthen its guidance. Jung called the adolescent as a binary stage of life-a kind of resistance/acceptance of the dual structure, full of all kinds of conflicts. As we described above, youth culture has both positive and negative functions. After the 80s of this century, the core of China's social and cultural development has changed into material culture, the spiritual culture has released the burden, yet it is relatively vulnerable. The culture has not gotten a balanced development, as a result, the problems will be exposed naturally as time goes by. Culture is rich and diverse, but lack of regulation, which reflects in both the management of cultural transmission channels and the management of cultural contents. After China's reform and opening-up, through various channels, some non-rational, vulgar, superstitious ideas reach youth's spiritual world without hindrance, which lets some youth who are in an unstable personality state go astray. For example, people born in the 70's pursue the diversity and freshness of life. Bars, rock, sex and nightlife become their label. This kind of lifestyle, which also has both positive and negative sides, is caused by foreign culture. If one is indulged in, it is actually a kind of depravation. Conversely, it is to release the stress from the city life. As people has analyzed from the perspective of functionalism, youth culture itself does not have any praise or derogatory meaning. However, if we do not choose the foreign culture carefully which is shared and accepted by youth and let culture flow into disorder, this will inevitably lead to its contradictory opposite of bad direction. As a result, there will be the depravation of youth-violent crime, terrorism, drug trafficking and demoralization, etc. which is described by pessimism young sociologist.

\section{Conclusion}

As youth culture has trait of hierarchy, variability and rebellion, we should take actions from two aspects when we strengthen the positive guidance function of advanced culture. Firstly, we ought to start from the management of the dissemination content. Youth culture is not only a popular culture, but also a phenomenon of public social psychology. Many people in society pursue a certain lifestyle, which makes this lifestyle seen everywhere in a relatively short time and causes a chain reaction between people. Mass media plays a vital role in this process, so selecting the positive, healthy and advanced communication materials can create active guidance for youth culture. Secondly, we should strengthen the management of communication means. Modern media is a multi-dimensional information channel which consists of television, movies, newspapers and networks. China does very well in all aspects except the network management, to which we have to pay more attention. The network allows the recipients of information to become more active and it's very popular among the young people yearning for independence, so the network users are mostly young. Nevertheless, more and more network crime, which is undoubtedly a great discredit of the youth image at the same time, points out the focus and direction of our work-scientific management and reasonable guidance to create a good external environment for the prosperity of youth culture. Only in this way can we ensure that the youth culture can be more developed and boomed.

\section{Acknowledgments}

The research is supported by Collaborative Innovation Center for the Southwestern University's Balanced Urban-Rural Public Cultural Service (No.13SWUGGFWB10).

\section{REFERENCES}

Fei, X. T. (1985). America and the Americans (pp. 26-37). Shanghai: SDX Joint Publishing Company.

Hao, M. X. (1996). The characteristics and development trend of modern youth culture. Academic Journal of Jinyang, 2, 108-110.

Huang, Z. J. (1993). Comparison of Chinese and foreign youth culture (pp. 1-32). Beijing: China Youth Press.

José, M. P. (2001). Transition and youth culture: Forms and performance. International Social Science Journal, 2, 93-105.

Li, Y. B. (1997). Commercial development and youth culture. Youth Studieds, 12, 12-14.

Wei, Q. L. (1996). Research handbook of sociology in china and foreign countries (pp. 130-133). Beijing: China Social Sciences Press.

Yao, W. F. (2000). Youth culture-Contemporary aesthetic criticism. A Multidimensional Study of Orientalism, 3, 227-240. 